\title{
Kinematics and Dynamics of the Ballistic Impact Behavior for an Oil Palm Empty Fruit Bunch Fiber Reinforced Bio-Composite
}

\begin{abstract}
Siti Nikmatin, ${ }^{\text {a,b }, *}$ Bambang Hermawan, ${ }^{\text {a }}$ Irmansyah, ${ }^{\text {a }}$ Mohammad Nur Indro, ${ }^{\text {a }}$ Mochammad Danny Sukardan, ${ }^{\mathrm{c}}$ and Rofiqul Umam ${ }^{\mathrm{d}}$

The ballistic impact behavior of oil empty fruit bunch fiber reinforced biocomposites was studied. Epoxy and polyester resins were used as the main material and were evaluated as a matrix to determine their capability. The ballistic test was performed using a $9 \mathrm{~mm}$ handgun and a jacketed hollow point round. A model based on kinematics and dynamics was used to calculate the decrease in velocity of the projectile with a constant deceleration. The energy lost during the impact was calculated based on the theory of kinetic energy. The epoxy bio-composite was able to hold a projectile more successfully than the polyester bio-composite at a certain penetration depth. The curve of the decrease in velocity for both of the resins was exponentially distributed. An 18\% epoxy bio-composite was able to more successfully stop the projectile at a penetrative depth of 2.14 $\mathrm{mm}$ and was able to absorb all the kinetic energy generated (408 J).
\end{abstract}

Keywords: Deceleration; Kinetics energy; Penetrating depth; Striking velocity

Contact information: a: Department of Physics, Faculty of Mathematics and Natural Sciences, Bogor Agricultural University, Bogor, West Java 16680 Indonesia; b: Surfactant and Bioenergy Research Center - IPB University, Bogor, West Java 16143 Indonesia; c: Center for Textiles, Bandung, West Java 40272 Indonesia; d: School of Science and Technology, Kwansei Gakuin University, Nishinomiya, Hyogo 6628501Japan; *Corresponding author: snikmatin@apps.ipb.ac.id

\section{INTRODUCTION}

In recent years, natural fibers have attracted the attention of biomaterial scientists. Researchers from various countries and industries have attempted to determine any specific advantages of natural fibers in comparison to conventional or synthetic fibers. Primary motivations for an increased interest in the research of natural fibers are the environmental problems that concern the world. This problem has become a national and international agenda; therefore, biodegradable natural or bio-based fibers, e.g., synthetic fibers, have been the center of research in the materials field for the last decade (Mohanty et al. 2005). Additional reasons include: low cost, light-weight nature, specific properties that are comparable to synthetic fibers, ease of separation, sequestration of carbon dioxide, noncorrosive nature, and the ability to reduce machine, heat (global warming), and respiratory irritation (Abdurrahman et al. 2019; Irzaman et al. 2019). These reasons have led to increasing interest in the use of natural materials (bio fiber) as a substitute for synthetic materials, which is the primary topic in the field of biomaterials (Chauhan and Chauhan 2013).

Bio-composite applications can be useful for households, as well as having more specific benefits, e.g., such as in airplane spaces, where glass is replaced with natural fiber composites, and in some interior car parts, such as panels (Sahari and Sapuan 2012). 
Industrial environments, such as the automotive industry, have noted that throughout human history there has been a need for protection from injury stemming from dangerous situations. There is an abundance of technical data that recognizes armor made with steel; however, its density is not appropriate for usage as light body armor (Nikmatin et al. 2015). One of the greatest challenges for researchers is to create lighter materials that are able to reach the same level or exceed the level of protection that steel provides, but in such a way that the speed and mobility of the user are not impeded (Fowler et al. 2008).

Improved technology in the bio-composite industry has increased the interest researchers have shown to natural fibers as a substitute material to synthetic fibers (Bahraoui et al. 2016). The reinforcement materials used in composites have been categorized as natural fibers and synthetic materials (Sahariand Sapuan 2012). Several attempts have been made to explore the application of natural fibers as a bio-composite, using materials such as banana plant biomass, rattan, almond shells, nut-shell, and palm oil. More recent attempts have focused on the provision of renewable and biodegradable material sources (Hermawan et al. 2017).

A considerable amount of literature has been published on the usage of synthetic fibers in terms of protection (Buggy 2006). However, there has been little discussion on the ballistic impact behavior of natural fibers (Mohanty et al. 2005). Although research has been performed on ramie, jute, and the curious fiber (Ananas erectifolius), no study existed for fibers from oil palm (Nikmatin et al. 2018).

The present work aimed to evaluate the ballistic impact behavior of bio-composite reinforced oil palm fibers, which were impregnated with a thermosetting resin using onedimensional kinematics. Several bio-composite plates were manually manufactured by pouring resin on fibers and allowing to cure. Finally, to demonstrate and analyze the performance of the plates in terms of protection, a ballistics test was performed using a 9 $\mathrm{mm}$ gun with a jacketed hollow point (JHP) round.

\section{Theories}

Conservation of momentum is a useful tool for discussing the collision process. Impulse is a vector quantity in the same direction as the force direction. Collision events between two objects can be divided into several types (Soydan et al. 2018). The difference in collisions can be determined based on the value of the elasticity coefficient (coefficient of restitution) of the two colliding objects (Courtney and Courtney 2008). The coefficient of elasticity of two colliding objects is the same as the negative ratio between the difference in velocity after collision and the difference in velocity before a collision. The coefficient of elasticity is expressed as " $e$ ", which has a value greater than 0 but less than 1 , depending on the nature of the collision (Phadnis et al. 2015).

The nature of a collision is divided into 3 types, with the first collision type being a "perfect resilience," which has a coefficient of elasticity of 1 . An example of a collision with perfect resilience is when two objects move toward each other, then collide, and then separate (Lee et al. 2003). The second type is a collision with "partial resilience", which has a coefficient of elasticity of greater than 0 but less than 1 . The third type of collision is a "not resilient" collision, in which all mechanical energy is absorbed, and the law of conservation of momentum is applied; after the collision, the objects merge, and the coefficient of restitution (also denoted by $e$ ) equals 0 (Figueiredo et al. 2018). This collision second type was the basic theory for this study. An illustration demonstrating the basic theory behind the collision in this study was illustrated in Fig. 1. 


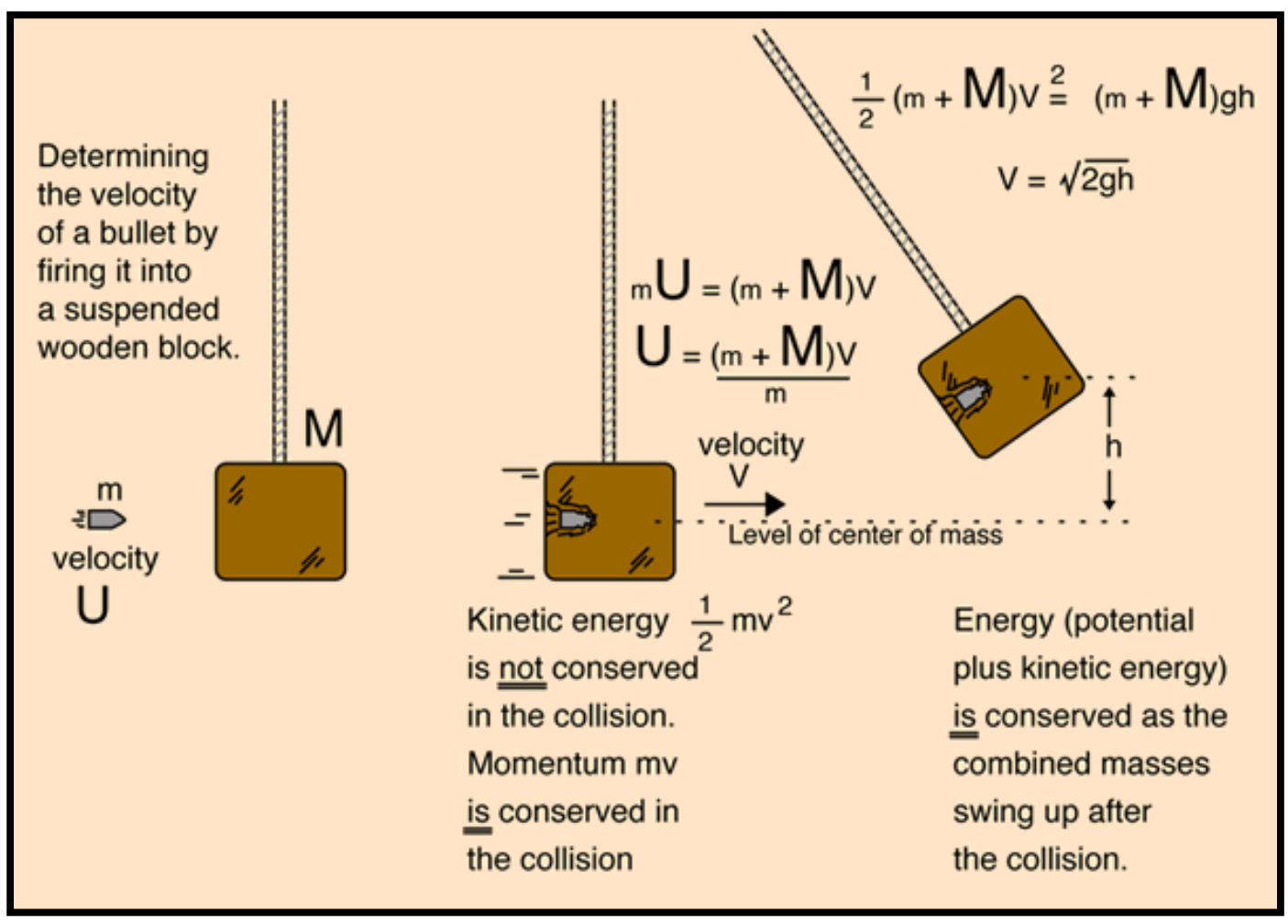

Fig.1. Illustration of collision as a relationship to kinetic energy and changes in velocity

The theoretical relationship described in Fig. 1 was used to determine the impact behavior of the three bio-composite materials subjected to ballistic testing via a gun and a JHP round. The resulting impact was the primary measurement tool in determining the penetrative resistance of oil palm empty fruit bunch (OPEFB) fibers.

\section{EXPERIMENTAL}

\section{Materials and Methods \\ Materials}

Raw OPEFB was obtained from PTPN VIII, Bogor, Indonesia. An epoxy resin (Eposchon), and a polyester resin (Yukalac 157) were obtained from a factory in Indonesia under licensing from Germany.

The final thickness of each laminate was $1 \mathrm{~cm}$ with concentrations corresponding to $6 \%, 12 \%, 15 \%$, and $18 \%$. In this study each test was conducted using 1 layer of lamination and 2 layers of lamination (later it was added that all test samples were 1 layer translucent). Furthermore, what is used in this paper are all the test samples made of 2 layers of lamination. So basically there is an increase in the value of $k$ (Hooke equation) in the test sample (Favor 2019) and an increase in fiber concentration.

\section{Non-woven OPEFB Fiber Fabrication}

The OPEFB fibers were soaked in tap water prior to the treatment. The crude fibers were dried at room temperature for $2 \mathrm{~d}$ and then stored (as shown in Fig. 2a). A non-woven machine was used to obtain a sheet of non-woven OPEFB fibers (as shown in Fig. 2b). 


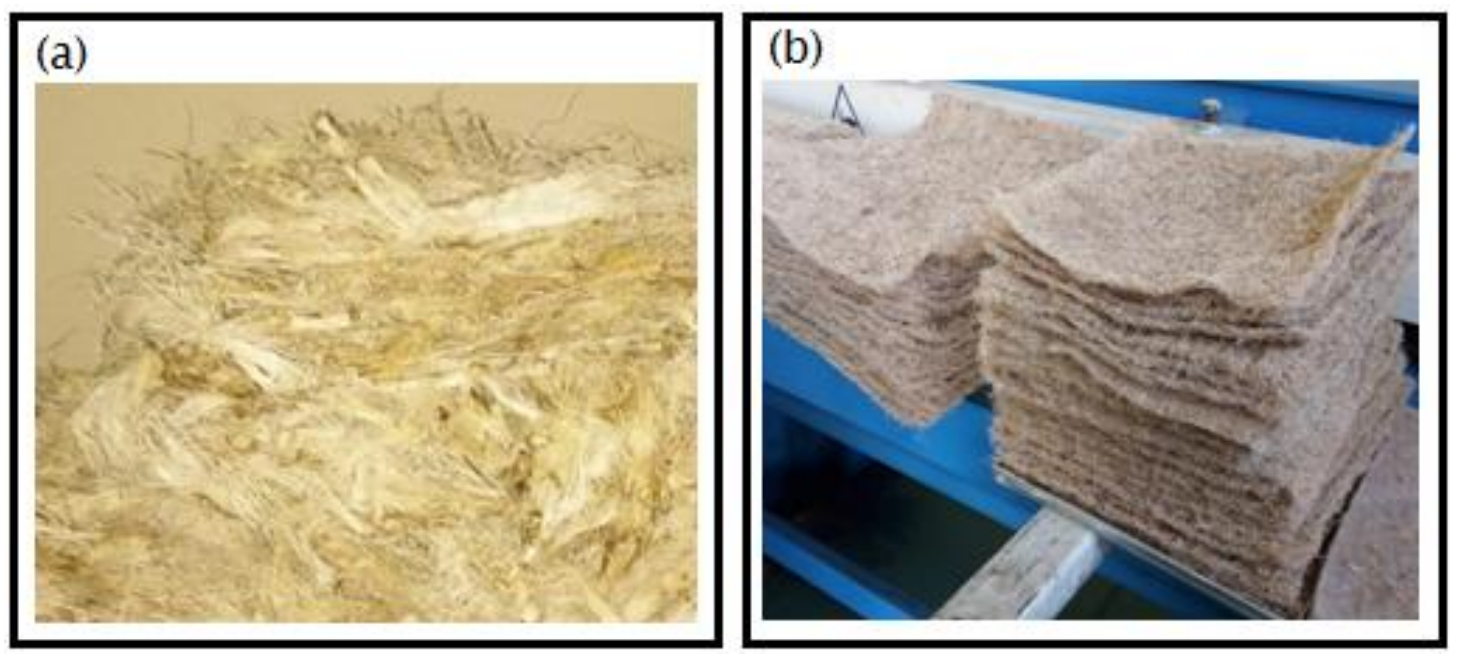

Fig. 2. (a) Raw material and (b) produced non-woven OPEFB fibers

\section{Bio-composite Fabrication}

Fabrication of the composites was carried out using a hot press method. The biocomposite materials were placed in molds with a dimension $30 \mathrm{~cm}$ x $30 \mathrm{~cm} \times 1 \mathrm{~cm}$ in depth, width, and height, respectively. Approximately $30 \mathrm{~g}(30 \mathrm{~cm} \mathrm{x} 30 \mathrm{~cm})$ of non-woven fiber sheet was placed into the mold, and the number of sheets was increased in order to achieve the necessary OPEFB fiber concentrations $(6 \%, 12 \%, 15 \%$, and 18\%). The epoxy resin was mixed with its hardener (at a 1 to 1 ratio), while the polyester was mixed with its hardener (at a 99 to 1 ratio). Then the mixtures were poured into their respective molds. To create the bio-composite plate, each mixture was pressed at around $390 \mathrm{~N} / \mathrm{m}^{2}$ with a constant temperature of $100{ }^{\circ} \mathrm{C}$ for $30 \mathrm{~min}$. The procedure was stopped and cooled to room temperature, after which the pressing process was resumed for 90 minutes the same pressure (around $390 \mathrm{~N} / \mathrm{m}^{2}$ ) and room temperature.

\section{Ballistic Test}

The ballistic test performed at a distance of 30 minutes using a pistol and was repeated three times. All of the ammunition (Table 1) and the pistol were produced by PTPindad (Bandung, Indonesia).

Table 1. Specifications of the Ammunition

\begin{tabular}{|c|c|}
\hline Specification & Information \\
\hline Average velocity & $320 \mathrm{~m} / \mathrm{s}$ \\
\hline Core material & Lead antimony \\
\hline Type & Jacketed hollow point \\
\hline Weight & 124 grains \\
\hline Propellant type & Smokeless powder \\
\hline Average gas pressure & Maximum of $2,600 \mathrm{~kg} / \mathrm{cm}^{2}$ \\
\hline Accuracy & $50 \mathrm{~m}$ \\
\hline PT. Pindad (2019) & \\
\hline
\end{tabular}

Composites are made by considering the concentration, temperature, and time of manufacture (Lin modification 1992). Concentrations were made according to the values in the data sheet (Bakelite Korea Co., Ltd). The EEW value was $188.8 \mathrm{~g} / \mathrm{eq}$ and the amine value was $66.8 \mathrm{~g} / \mathrm{eq}$. So for every $188.8 \mathrm{~g}$ of epoxy, $66.8 \mathrm{~g}$ of amine was used. For polyester 
resin a 1phr mass ratio was used (Lin 1992). Furthermore, the temperature used at the optimum exothermic temperature was $100{ }^{\circ} \mathrm{C}$. The time used for epoxy was $300 \mathrm{~min}$, whereas $90 \mathrm{~min}$ was used for polyester resin.

\section{RESULTS AND DISCUSSION}

\section{Kinematics and Penetration}

A model was used to solve the ballistic impact problem in this study, which was based on an approach using single dimensional kinematics. First, a projectile was reviewed just before its collision. When a projectile leaves the muzzle, time and velocity have a simple relationship when the velocity is constant. The time needed by the projectile to hit the target is approximately $0.09375 \mathrm{sec}$, as shown in Eqs. 1 through 3,

$$
\begin{aligned}
& \text { Average velocity }=\frac{\text { displacement }}{\text { time elapsed }} \\
& \bar{v}=\frac{\Delta x}{\Delta t} \\
& \bar{v}=\frac{x-x_{0}}{t-t_{0}}
\end{aligned}
$$

where $\bar{v}$ is the average velocity of a projectile, $x$ is the amount of displacement, and $t$ is time.

Afterwards, a projectile was reviewed when the projectile, with a constant acceleration, reached the target surface and continued until the stopping point was reached. However, some assumptions were made for the proposed model: (1) the bio-composite was uniform across its shape; (2) the projectile did not deform or breakup during the impact due to its rigidity; and (3) a stable projectile that always pointed close to the trajectory.

As shown in the data in Table 2 , at a fiber concentration of $15 \%$, the epoxy biocomposite was able to stop projectiles past a depth of $2.30 \mathrm{~mm}( \pm 0.14)$, while polyester was only able to stop projectiles past a depth of $3.00 \mathrm{~mm}( \pm 0.10)$. In addition, when the fiber concentration was increased to $18 \%$, the epoxy bio-composite was able to able to stop projectiles past a depth of $2.14 \mathrm{~mm}( \pm 0.07)$, although the polyester bio-composite was only able to stop projectiles past a depth of $2.96 \mathrm{~mm}( \pm 0.14)$.

Table 2. Penetrating Depth $(\mathrm{mm})$ of Projectiles Fired at OPEFB Bio-composite

\begin{tabular}{|l|c|l|l|c|c|}
\hline & Control & $6 \%$ & $12 \%$ & $15 \%$ & $18 \%$ \\
\hline Epoxy & Perforation & Perforation & Perforation & $2.30 \pm 0.14$ & $2.14 \pm 0.07$ \\
\hline Polyester & Perforation & Perforation & Perforation & $3.00 \pm 0.10$ & $2.96 \pm 0.14$ \\
\hline
\end{tabular}

To solve the problem when the time $(t)$ was not known, the initial time was simplified to be zero. The average velocity was shown in Eq. 4,

$$
\bar{v}=\frac{x-x_{0}}{t}
$$

which could be rewritten in terms of $x$, as shown as Eq. 5,

$$
x=x_{0}+\bar{v} t
$$

where since the velocity increased at a proportional rate, the average velocity was half of the final and initial velocities, as shown in Eq. 6, 


$$
\bar{v}=\frac{v_{0}+v}{2}
$$

and substituting Eq. 6 into Eq. 5 yielded Eq. 7,

$$
x=x_{0}+\left(\frac{v_{0}+v}{2}\right) t
$$

which could be solved for $x$ (displacement).

An object is said to be accelerating when its velocity changes, as defined in Eq.8, Eq. 9, and Eq. 10,

$$
\begin{aligned}
& a=\frac{\text { change of velocity }}{\text { time elapsed }} \\
& a=\frac{\Delta v}{\Delta t} \\
& a=\frac{v-v_{0}}{t-t_{0}}
\end{aligned}
$$

where $a$ is the average acceleration. Equation 10 can be rewritten in terms of $t$, with the initial time simplified to zero, as shown in Eq. 11,

$$
t=\frac{v-v_{0}}{a}
$$

and substituting Eq.11 into Eq.7 yielded Eq. 12,

$$
x=x_{0}+\left(\frac{v_{0}+v}{2}\right)\left(\frac{v-v_{0}}{a}\right)
$$

which was simplified into Eq. 13,

$$
x=x_{0}+\frac{v^{2}-v_{0}^{2}}{2 a}
$$

and further simplified into Eq. 14,

$$
v^{2}=v_{0}^{2}+2 a\left(x-x_{0}\right)
$$

which could be solved for $v$ (velocity).

Table 3 presents the results of the deceleration calculations, according to Eq.14. As shown in Table 3, the deceleration rate was surprisingly high. The epoxy bio-composite was able to decrease the penetrative depth of a projectile better than the polyester biocomposite. Interestingly, this correlation was related to the concentration of fiber used to reinforce the matrix. The amount of filler fibers in a composite material is related to the ability of the composite to provide good mechanical properties (Silva et al. 2014). This is true as long as the optimum conditions have not been exceeded, since most composites are brittle and can only absorb energy and utilized a mage mechanisms; composites are not capable of plastic deformation. This was in accordance with an earlier observation, which showed that the fiber volume fraction had greater interaction with the projectile over the resin area.

Table 3. Deceleration $\left(\mathrm{m} / \mathrm{s}^{2}\right)$ of Projectiles Fired at OPEFB Bio-Composite Plate

\begin{tabular}{|c|c|c|}
\hline & $15 \%$ & $18 \%$ \\
\hline Epoxy & $2.23 \mathrm{E}+07 \pm 1.16 \mathrm{E}+06$ & $2.39 \mathrm{E}+08 \pm 7.73 \mathrm{E}+05$ \\
\hline Polyester & $1.71 \mathrm{E}+07 \pm 4.94 \mathrm{E}+05$ & $1.73 \mathrm{E}+07 \pm 7.64 \mathrm{E}+05$ \\
\hline
\end{tabular}


Figure 3 shows the results of the observations of the ballistic tests in terms of their kinematic relationships (the decreased bullet velocity to penetration). The line trend clearly shows that the decrease in velocity to the decrease in penetrative depth formed an exponential function line. In general, this meant that the characteristics of the material used in this study had a major impact on speed reduction, even though it was shown in Fig. 3 that both resins (epoxy and polyester) had drastically different points of decline. The 18\% and $15 \%$ epoxy resins had approximately equal speed drop points, which started at a depth of $\pm 0.0016 \mathrm{~m}$ and at a speed of $\pm 160 \mathrm{~m} / \mathrm{s}$. The $15 \%$ and $18 \%$ polyester resins had approximately equal speed reduction points at a depth of $\pm 0.0025 \mathrm{~m}$ and at a speed of \pm $132 \mathrm{~m} / \mathrm{s}$. However, out of the four concentration of resin used, the $18 \%$ epoxy resin had the best results, in terms of reducing bullet speed and the least amount of penetrative depth.

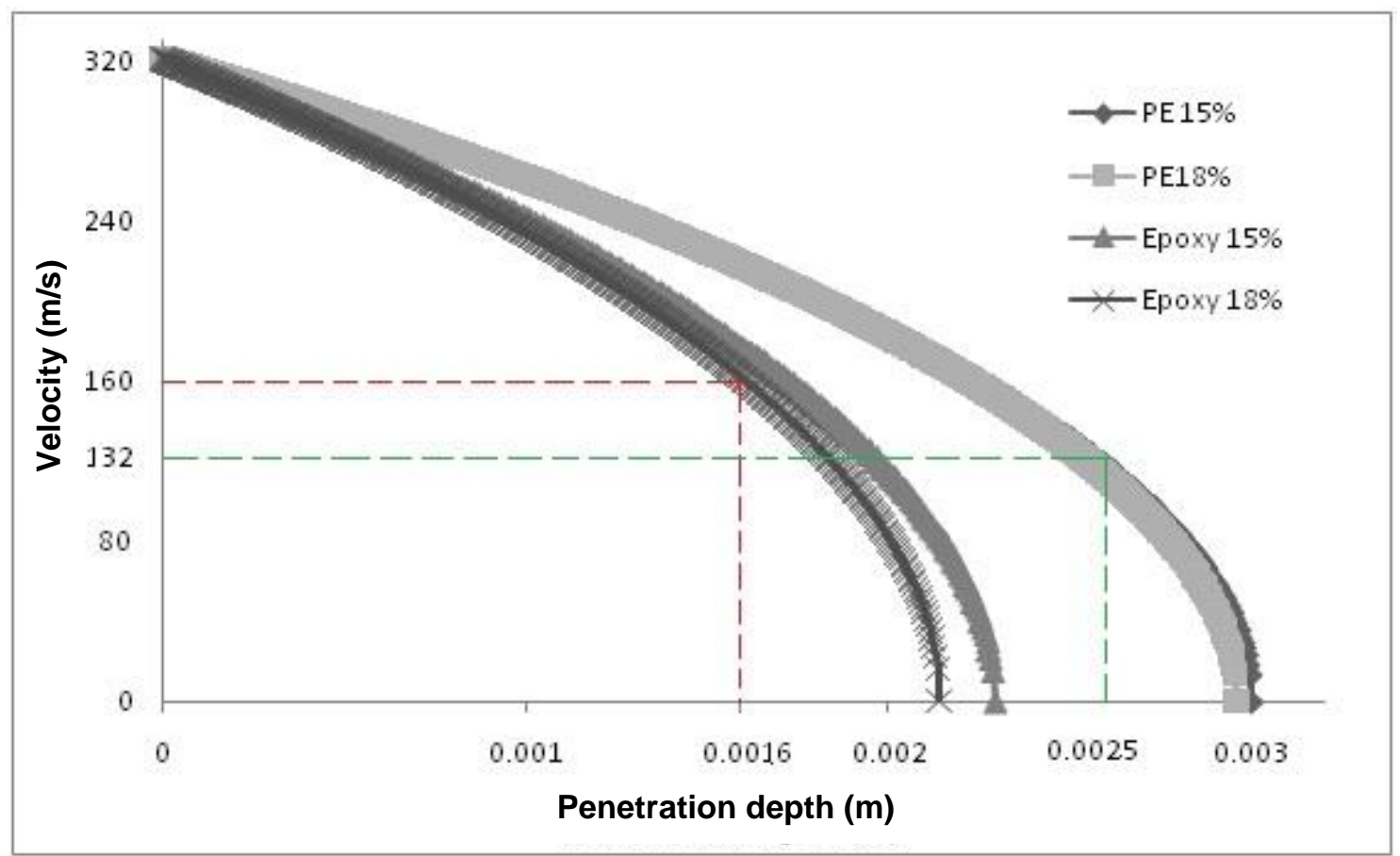

Fig. 3. The decrease in velocity of the projectiles fired at the OPEFB bio-composite plate

\section{Dynamics and Blunt Impact}

The ability of bullets to cause injury to human tissue is known as wounding power, and theories that relate wounding power to energy kinetic have been accepted. However, these theories have misconceptions, since they do not consider the interactions between the targets and the projectiles. Since the rate of deceleration (Table 3) was considered constant, the total energy of the projectile was lost when the maximum penetrative depth was obtained. The concept of energy refers to kinetic energy (Resnyansky and Katselis 1993). Since the kinetic energy (KE) of a projectile depends on the mass of a projectile moving at a specific velocity, KE was calculated according to Eq. 15,

$$
K E=\frac{1}{2} m v^{2}
$$

where $m$ is the mass, and $v$ is the velocity.

The energy lost during impact (EL) was calculated according to Eq. 16, 


$$
E L=\frac{1}{2} m\left(v_{s}^{2}-v_{r}^{2}\right)
$$

where $v_{s}$ is velocity after collision and $v_{r}$ is velocity before collision.

Ballistic testing (with a velocity range of $50 \mathrm{~m} / \mathrm{s}$ to $1000 \mathrm{~m} / \mathrm{s}$ ) has been categorized as a high velocity impact. However, this categorization has long been debated in various literature. This categorization was important due to the extreme changes in the total energy transfer between the projectile and the target, as well as the total energy dissipation and the damage propagation mechanisms, which are dependent on the velocity of the projectile (Resnyansky and Katselis 1993).

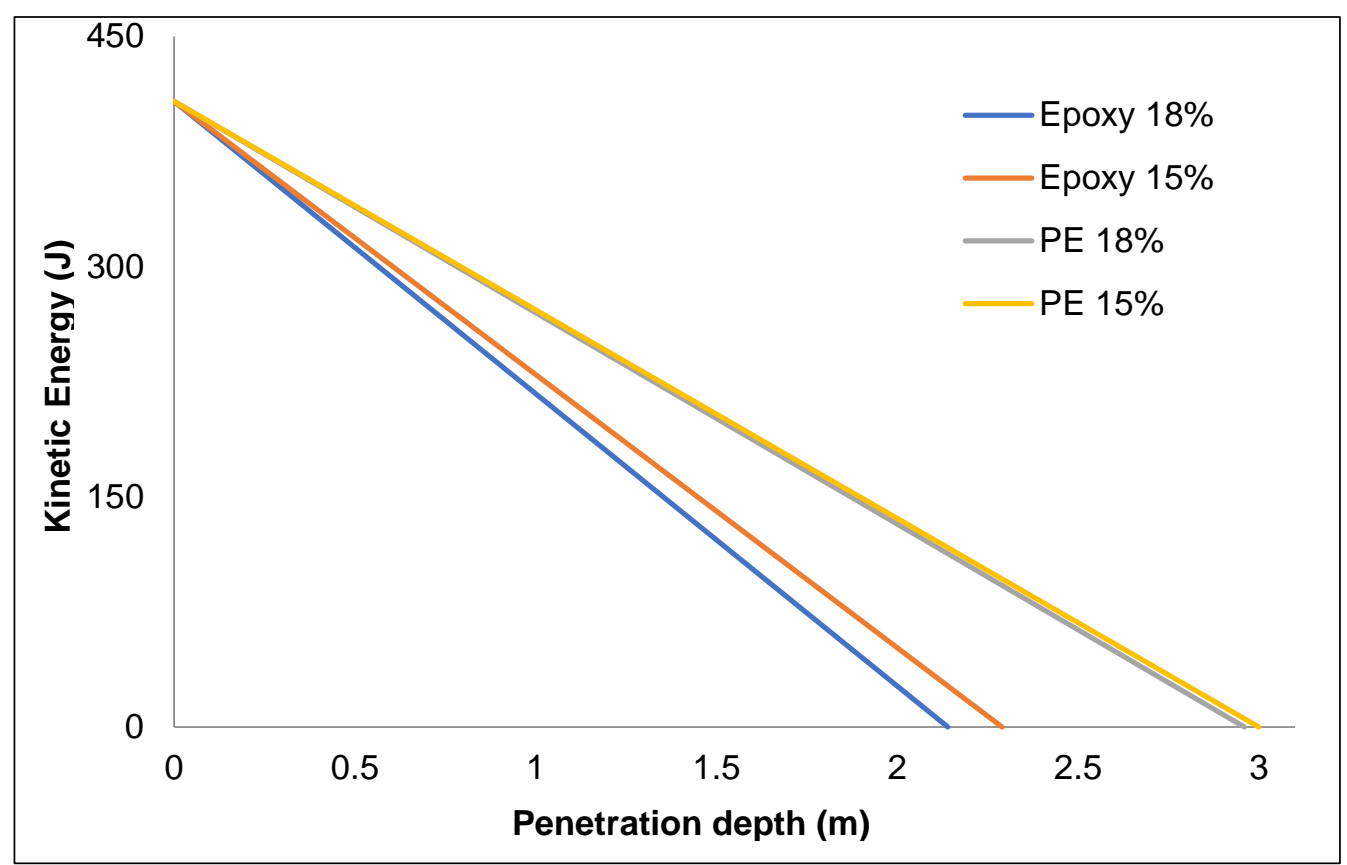

Fig. 4. The energy absorbed from projectiles fired at the OPEFB bio-composite plate

As shown in Fig. 4, the $18 \%$ epoxy resin was able to more successfully stop the projectile at a penetrative depth of $2.14 \mathrm{~mm}$ and was able to absorb all the kinetic energy generated (408 J). The low-velocity projectile was produced using a handgun, and due to its short barrel length, deposited all of its energy in the target. This provided interesting results. When performing ballistic testing using JHP ammunition, the use of an $18 \%$ epoxy resin was the superior bio-composite in terms of kinematics and penetration tests, and also had the greatest kinetic energy absorption value out of the four materials (Solikhin et al. 2019).

In addition, an Izod impact test was also conducted to see the deformation capability of the composites. Table 4 shows information about the impact test.

Table 4. ANOVA Table for Impact Izod Test (KJ/m)

\begin{tabular}{|l|l|l|l|l|l|}
\hline Source & DF & Adj SS & Adj MS & F-Value & P-Value \\
\hline Factor & 5 & 76487 & 15297 & 338,82 & 0,000 \\
\hline Error & 23 & 9063 & 394 & 0 & \\
\hline Total & 28 & 85549 & & & \\
\hline
\end{tabular}


Because the mechanical test results had p-values less than $0.05(0.000)$, it can be concluded that there was a significant difference among the population means. Therefore, it is appropriate to continue further impact Izod testing using Fisher LSD.

Table 5. ANOVA Table for Impact Izod Test $(\mathrm{KJ} / \mathrm{m})$ with a Group using Fisher LSD

\begin{tabular}{|l|l|l|}
\hline Factor & Mean $\mathbf{k J} / \mathbf{m}$ & Group \\
\hline Epoxy $18 \%$ & 163.1 & A \\
\hline Epoxy $15 \%$ & 150.0 & A B \\
\hline PE18\% & 126.4 & B \\
\hline PE 15\% & 95.2 & C \\
\hline PE Ctrl & 36.5 & D \\
\hline Epoxy Ctrl & 32.3 & D \\
\hline
\end{tabular}

Means that do not share a letter are significantly different.

Table 5 shows the results of the Izod impact test, using the Fisher LSD method. If all the treatments were compared with the control without fiber, it was seen that all the addition of fiber treatments would improve the mechanical properties of the composite. In this case the stress that occurs in the test material can be effectively transferred between the filler and the matrix (Hermawan 2017).

Furthermore, Epoxy $18 \%$ and $15 \%$ were not significantly different with respect to being able to withstand deformation. Increasing the amount of fiber (Epoxy 15\%, Epoxy $18 \%$ and PE18\%) does not greatly affect the resistance of the composite to deformation (Figs. 5 and 6).

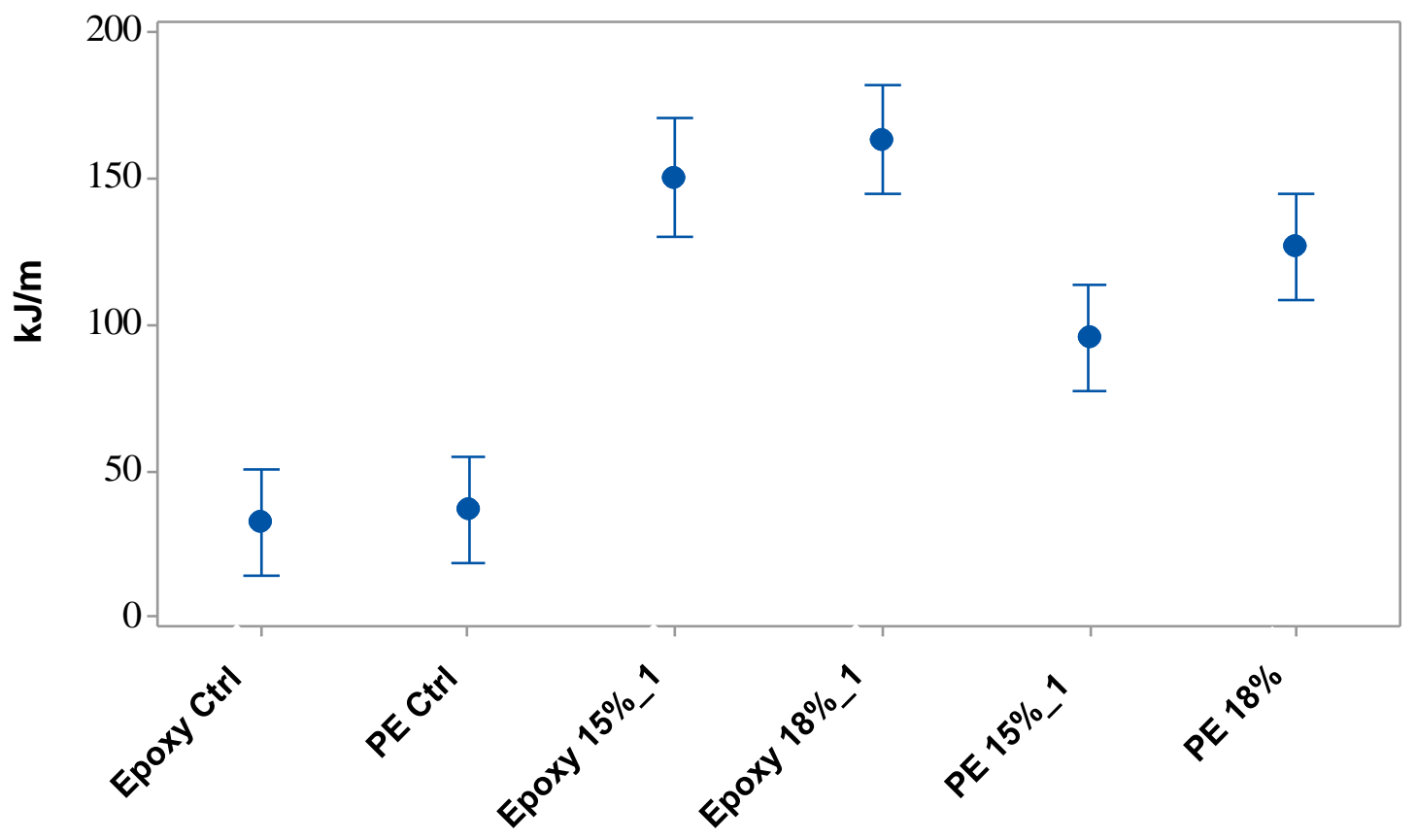

The pooled standard deviation was used to calculate the intervals.

Fig. 5. The Izod impact plot intervals at $95 \%$ confidence intervals were significantly different in the treatment. 


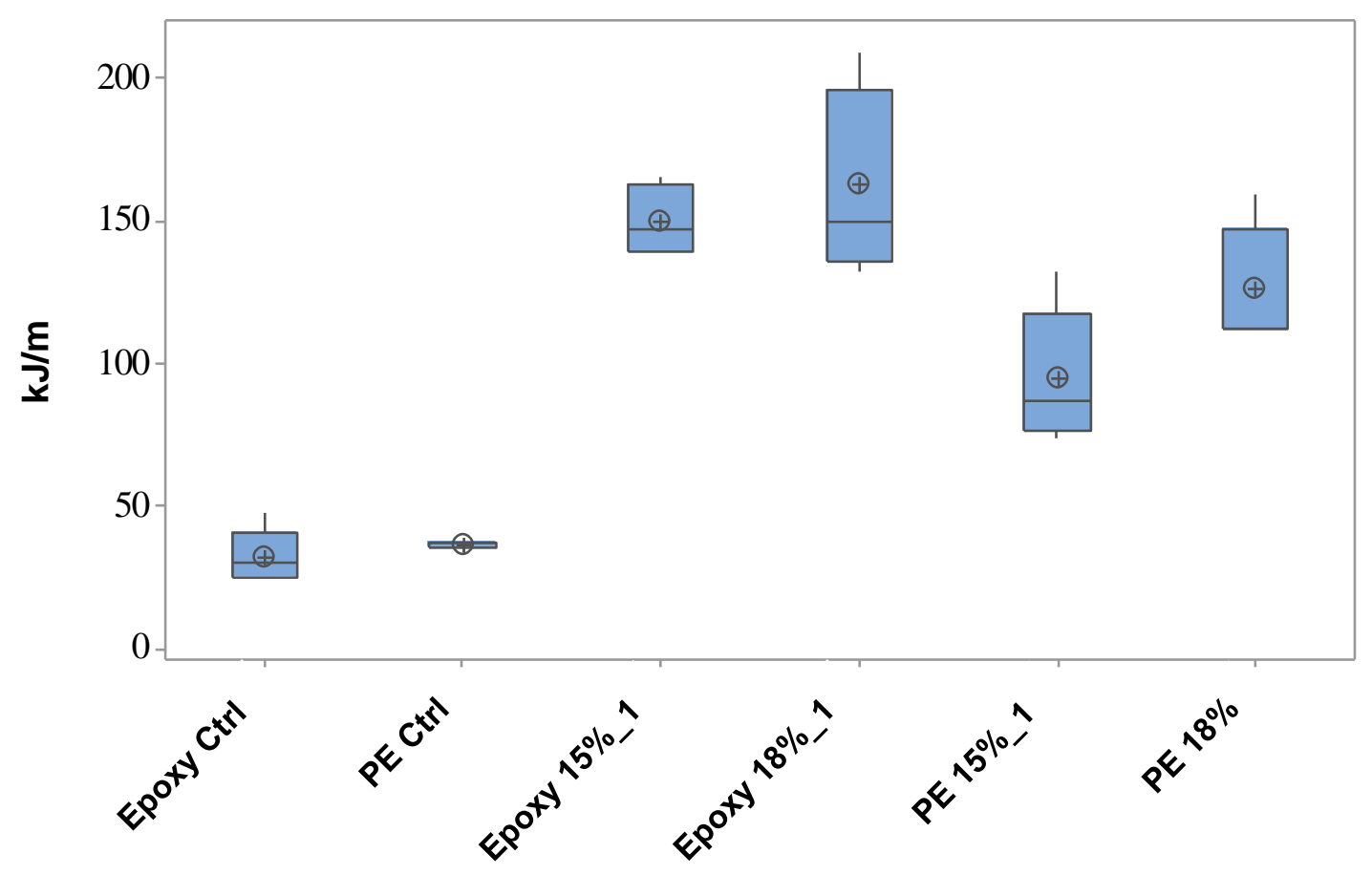

Fig. 6. Izod's impact box plot

\section{CONCLUSIONS}

1. Observations from the ballistic testing on the use of oil empty fruit bunch fibers (OPEFB) to prepare reinforced bio-composites yielded promising results. Even though the velocities documented from the kinematics and bullet penetration test results had the same trend (exponential), bio-composites that used an epoxy resin had greater success than the polyester resin bio-composites.

2. In addition, the kinetic energy absorption rate of the four bio-composites synthesized from oil empty fruit bunch fibers (OPEFB) were similar. However, the use of an epoxy resin yielded the highest absorption rate.

3. The use of oil empty fruit bunch fibers (OPEFB) as a bio-composite, based on the ballistic test results in terms of their ability to reduce speed, reduce penetrative depth, and show sufficient kinetic energy absorption rates, had excellent results.

\section{ACKNOWLEDGMENTS}

The present work was fully funded by the Indonesia Oil Palm Estate Fund [Badan Pengelola Dana Perkebunan Kelapa Sawit (BPDPKS)], Ministry of Finance, Republic of Indonesia. The authors give their thanks for the support of the Indonesian Ministry of Research, Technology and Higher Education. 


\section{REFERENCES CITED}

Abdurrahman, A., Umam, R., Irzaman,I., Palupi, E. K., Saregar, A., Syazali, M., Junaidi, R., Wahyudianto, and Adi, L. C. (2019). "Optimization and interpretation of heat distribution in sterilization room usingconvection pipe," Indonesian Journal of Science \& Technology 4(2), 204-219.

Bahraoui, I., Elminor, H., Elminor, H., Hilali1, E., and Kanit, T. (2016). "Mechanical characterization and homogenization approach of a bio-composites based on PP reinforced with nut-shells of argan," IOSR Journal of Mechanical and Civil Engineering 13(6), 43-50.

Buggy, M. (2006). "Natural fibers, biopolymers, and biocomposites," Polymer International 55(12), 1462-1462. DOI:10.1002/pi.2084

Chauhan, A., and Chauhan, P. (2013). "Natural fibers and biopolymer," Journal of Chemical Engineering \& Process Technology 6, 1-4. DOI:10.4172/2157-7048.s6-001

Courtney, M., and Courtney, A. (2008). The Ballistic Pressure Wave Theory of Handgun Bullet Incapacitation, Cornell University, Ithaca, NY.

Figueiredo, A. B.-H. da S., Lima Júnior, É. P., Gomes, A. V., Melo, G. B. M. de, Monteiro, S. N., and Biasi, R. S. de. (2018). "Response to ballistic impact of aluminaUHMWPE composites,"Materials Research 21(5). DOI:10.1590/1980-5373-mr2017-0959

Fowler, P. A., Hughes, J. M., and Elias, R. M. (2008). "Biocomposites: Technology, environmental credentials and market forces," Journal of the Science of Food and Agriculture 86(12), 819-823.DOI: 10.1002/jsfa.2558

Hermawan, B., Nikmatin, S., Sudaryanto, Alatas, H., and Sukaryo, S. G. (2017). "Effect of oil palm empty fruit bunches fibers reinforced polymer recycled," in: Innovation in Polymer Science and Technology 2016, Medan, Indonesia, pp. 1-10. DOI: 10.1088/1757-899X/223/1/012064

Irzaman, I., Cahyani, I. D., Aminullah, A., Maddu, A., Yuliarto, B., and Siregar, U. (2019). "Biosilica properties from rice husk using various HCL concentrations and frequency sources," Egyptian Journal of Chemistry. Article in Press. DOI:10.21608/EJCHEM.2019.8044.1679

Lee, Y. S., Wetzel, E. D., and Wagner, N. J. (2003). "The ballistic impact characteristics of Kevlar ${ }^{\circledR}$ woven fabrics impregnated with a colloidal shear thickening fluid," Journal of Materials Science 38(13), 2825-2833. DOI:10.1023/A:1024424200221

Mohanty, A. K., Misra, M., Drzal, L. T., Selke, S. E., Harte, B. R., and Hinrichsen, G. (2005). "Natural fibers, biopolymers, and biocomposites: An introduction," in: Natural Fibers, Biopolymers, and Biocomposites, A. K. Mohanty, M. Misra, and L. T. Drzal (eds.), CRC Press, Boca Raton, FL, pp. 10-36.

Nikmatin, S., Hermawan, B., Irmansyah, I., Indro, M. N., Kueh, A. B. H., and Syafiuddin, A. (2018). "Evaluation of the performance of helmet prototypes fabricated from acrylonitrile butadiene styrene composites filled with natural resource," Materials 12(1), 1-12. DOI:10.3390/ma12010034

Nikmatin, S., Syafiuddin, A., Kueh, A. B. H., and Purwanto, Y. A. (2015). "Effects of nanoparticle filler on thermo-physical properties of rattan powder-filled polypropylene composites," Jurnal Teknologi 77(16), 1-6. DOI: 10.11113/jt.v77.6415

Phadnis, V. A., Pandya, K. S., Naik, N. K., Roy, A., and Silberschmidt, V. V. (2015). "Ballistic damage in hybrid composite laminates," in: $11^{\text {th }}$ International Conference on Damage Assessment of Structures (DAMAS 2015), Ghent, Belgium, pp. 0-8. 
DOI: $10.1088 / 1742-6596 / 628 / 1 / 012092$

PT. Pindad (2019). "MU1-JHP," (https://www.pindad.com/mu1-jhp),Accessed August 20, 2019.

Resnyansky, A. D., and Katselis, G. (1993). Ballistic and Material Testing Procedures and Test Results for Composite Samples for the TIGER Helicopter Vulnerability Project (DSTO-TR-1617), Australian Government Department of Defense Defence Science and Technology Organisation Systems Sciences Laboratory, Edinburgh, Australia.

Sahari, J., and Sapuan, S. M. (2012). "Natural fibre reinforced biodegradable polymer composites," Reviews on Advanced Materials Science 30(2), 166-174.

Silva, M. V., Stainer, D., Al-Qureshi, H. A., Montedo, O. R. K., and Hotza, D. (2014). "Alumina-based ceramics for armor application: Mechanical characterization and ballistic testing," Journal of Ceramics 2014, 1-6. DOI:10.1155/2014/618154

Solikhin, A., Hadi, Y. S., Massijaya, M. Y., and Nikmatin, S. (2019). "Nanostructural, chemical, and thermal changes of oil palm empty fruit bunch cellulose nanofibers pretreated with different solvent extractions," Waste and Biomass Valorization 10(4), 953-965. DOI: 10.1007/s12649-017-0098-4

Soydan, A. M., Tunaboylu, B., Elsabagh, A. G., Sari, A. K., and Akdeniz, R. (2018). "Simulation and experimental tests of ballistic impact on composite laminate armor," Advances in Materials Science and Engineering 2018, 1-12.

DOI: $10.1155 / 2018 / 4696143$

Article submitted: October 30, 2019; Peer review completed: March 21, 2020; Revised version received and accepted: April 9, 2020; Published: June 24, 2020.

DOI: 10.15376/biores.15.3.6123-6134 